\title{
A case of type 1 von Willebrand disease with hypothyroidism
}

\author{
Azyan Shafeek ${ }^{1}$, Stella G de Silva ${ }^{2}$ \\ Sri Lanka Journal of Child Health, 2002; 31: 92-3
}

(Key words: type 1 von Willebrand disease, hypothyroidism)

\section{Introduction}

von Willebrand disease (vWD) is the most common congenital bleeding disorder affecting at least $1 \%$ of the population ${ }^{1}$. von Willebrand factor (vWF) is a cofactor for platelet adhesion and a carrier protein for factor VIII procoagulant, synthesized in the endothelial cells and megakaryocytes ${ }^{1}$. More than 20 sub types have been recognized ${ }^{1}$. Major subtypes are:

Type I - A mild to moderate quantitative decrease in the plasma levels of vWF.

Type II - Qualitative defect of vWF structure.

Type III - Total absence of vWF.

Patients usually present with recurrent epistaxis or cutaneous hemorrhages ${ }^{1}$. Our patient is a Type 1 vWD associated with hypothyroidism.

\section{Case report}

A 10 year old boy from Colombo was admitted to Durdans hospital in March 2001 with a history of epistaxis, haematemesis and giddiness. There was a past history of two similar episodes, since 1997.

He is a known case of hypothyroidism diagnosed at the age of three years (TSH $>50$, carpal bones 2 in number) and is on thyroxine. In 1997 he was diagnosed as vWD in Sri Lanka, when he first presented with haematemesis. (bleeding time $>12 \mathrm{mts}$, normal prothrombin time (PT), prolonged activated partial thromboplastin time (APTT). This was confirmed by the platelet aggregometry, factor VIII assays and coagulation profile at Apollo hospital, India in 1999. There is no family history of vWD or any other bleeding disorders.

On examination the boy was conscious but drowsy. The pulse rate was $140 /$ min with warm extremities.

${ }^{1}$ House Officer (paediatric unit), Durdans Hospital, Colombo. ${ }^{2}$ Consultant Paediatrician
The blood pressure was 90/50 mm $\mathrm{Hg}$. He was pale, but there were no other positive signs.

The haemoglobin was $6.7 \mathrm{~g} / \mathrm{dl}$, bleeding time $>10$ minutes, PT 15 seconds (control 13 seconds) APTT 70 seconds (control 36 seconds). The TSH was 11.0 (normal range 0.2-3.8), T4 was 0.5 (normal range $5.1-13.0 \mu \mathrm{g}$ ) and $\mathrm{T} 3$ was $1.10 \mu \mathrm{g}$ (normal range 0.8 $2.0 \mu \mathrm{g})$.

He was transfused with cryoprecipitate and fresh frozen plasma. Packed red cells were given for the anaemia. Intranasal desmopressin was started along with oral tranexamic acid. The dose of thyroxine was increased to $150 \mu \mathrm{g}$ daily. Symptoms improved within $24 \mathrm{hrs}$. He was discharged asymptomatic.

\section{Discussion}

Of those children identified as having vWD, 70-80\% have type I disease ${ }^{1}$. In our child with type $1 \mathrm{vWD}$, a diagnosis of hypothyroidism was made at the age of 3 years and the child is on regular thyroxine therapy up to date. The first bleeding manifestation only occurred at the age of 6 years and since then he has had 2 further bleeding episodes while on maintenance thyroxine therapy.

In some cases, vWD is believed to result from other pathologic processes. For instance, children with Wilms tumour may have acquired vWD which resolves with treatment of the malignancy ${ }^{2}$. Secondary type 2 vWD has been identified in patients with congenital heart disease ${ }^{3}$. vWD caused by anti vWF antibodies has been documented in patients with systemic lupus erythematosus ${ }^{4}$. However, hypothyroidism is the commonest cause of acquired $\mathrm{vWD}^{5,6}$ and unlike most other acquired forms, hypothyroidism-associated vWD is usually type 1 .

Our patient is currently on oral thyroxine $150 \mu \mathrm{g}$ daily and is advised to start on intranasal desmopressin and oral tranexamic acid when there is epistaxis or any mucosal bleeding immediately. $\mathrm{He}$ is advised hospitalization if bleeding persists despite above 
measures. He has been under constant supervision by one of us and he is reviewed regularly. He has had no bleeding episodes since the last in March 2001. In June 2002 the TSH was 0.053 (normal range 0.2-3.8).

\section{Acknowledgements}

We thank Dr. Mahinda de Alwis, Consultant Heamatologist, for making the initial hematological diagnosis.

\section{References}

1. Werner E J. von Willebrand disease in children and adolescents. Paediatric Clinics of North America 1996; 43: 683-707.

2. Scott J P, Montgomery R R, Tubergen D G. Acquired von Willebrand disease in association with Wilm's tumour: Regression following treatment. Blood 1981; 58: 665-9.
3. Gill J C, Wilson A D, Endres-Brooks J. Loss of the largest von Willebrand factor multimers from the plasma of patients with congenital cardiac defects. Blood 1987; 67: 758-61.

4. Soff $G$ A, Green D. Autoantibody to von Willebrand factor in systemic lupus erythematosus. J Lab Clin Med 1993; 121: 42430.

5. Bruggers $\mathrm{C}$ S, McElligot $\mathrm{K}$, Rallison $\mathrm{M}$ L. Acquired von Willebrand disease in twins with autoimmune hypothyroidism: Response to desmopressin and L-thyroxine therapy. Journal of Pediatrics 1994; 125: 911-3.

6. Coccia M R, Brnes H V. Hypothyroidism and acquired von Willebrand disease. Journal of Adolescent Health 1991; 12: 152-4. 
